\title{
Effects of tap water lead, water hardness, alcohol, and cigarettes on blood lead concentrations
}

\author{
S J POCOCK, ${ }^{1}$ A G SHAPER, ${ }^{1}$ MARY WALKER, ${ }^{1} \mathrm{C}$ J WALE, ${ }^{1}$ BARBARA CLAYTON, ${ }^{2}$ \\ T DELVES, ${ }^{2}$ R F LACEY,$^{3}$ R F PACKHAM,$^{3}$ AND P POWELL ${ }^{3}$ \\ From the Department of Clinical Epidemiology and General Practice, ${ }^{1}$ Royal Free Hospital School of Medicine, \\ London NW3 2QG, the Department of Chemical Pathology and Human Metabolism, ${ }^{2}$ University of \\ Southampton, and the Water Quality and Health Division, ${ }^{3}$ Water Research Centre, Medmenham, Marlow, \\ Bucks, UK
}

SUMmARY A survey of middle-aged men in 24 British towns has found pronounced geographical variation in blood lead concentrations. Towns with the highest mean blood lead concentrations have soft water supplies and have the highest water lead concentrations. Individual blood lead can be considerably increased by raised household tap water lead concentrations. Mean blood lead is estimated to be $43 \%$ higher for men when the concentration of lead in first-draw domestic tap water is $100 \mu \mathrm{g} / \mathrm{l}$ compared with a zero concentration. Individual blood lead is also affected by alcohol consumption and cigarette smoking, such that on average these two life-style habits together contribute an estimated $17 \%$ to the blood concentration of lead in middle-aged men. Lead in water should be given greater priority in any national campaign to reduce lead exposure.

There is considerable current concern about human exposure to lead, since evidence has been produced relating an increased body burden of lead to various health problems. The greatest effort by pressure groups has been brought to bear on the issue of lead in petrol, ${ }^{1}$ but our purpose here is to concentrate primarily on the problem of lead in drinking water.

The British Regional Heart Study was set up to investigate the pronounced geographical variation in mortality from cardiovascular disease. In its clinical survey of middle-aged men in 24 towns, blood lead and tap water lead were included as two factors worth studying in relation to risk of cardiovascular disease.

We describe the extent to which househod tap water lead concentrations affected blood lead concentrations in these middle-aged men. The effects of water hardness, alcohol consumption, and cigarette smoking on blood lead concentrations are also examined.

\section{Methods}

The British Regional Heart Study examined 7735 men aged 40-59 randomly selected from the age-sex registers of representative general practices in 24 British towns during the period January 1978 to June 1980. The criteria for selecting the towns, general practices, and subjects as well as the methods of data collection are reported elsewhere. ${ }^{2}$ The towns were primarily of size $50000-100000$ population, chosen to provide good geographical coverage and to cover the full range of cardiovascular mortality and water hardness. The group general practice selected in each town was required to have a social class distribution similar to that for all men in the town.

Blood lead analyses were carried out on 7378 men (95\%) using flame microsampling atomic absorption spectroscopy $^{3}$ with minor modifications to the original procedure: sample volumes were reduced to $6 \mu \mathrm{l}$, the wavelength was $217.0 \mathrm{~nm}, \mathrm{Al}_{2} \mathrm{O}_{3}$ absorption tubes were used, and the absorption signals were integrated. The missing samples were mainly accounted for by clotting problems in the specimens. To ensure comparability of blood-lead results over the two-year period of this study, a strict internal quality control protocol was maintained, and the quality of the analyses were assessed by participating in national and international quality assurance programmes.

Alcohol consumption was recorded for all men, using questions on frequency, quantity, and type similar to those used in the General Household Survey. Eight drinking categories were used: nondrinkers, men drinking infrequently or on special occasions, men drinking at weekends $(1-2,3-6$, or $>6$ drinks a day), and men drinking daily or on most days 
(1-2, 3-6, or $>6$ drinks a day). A "drink" was defined as half a pint of beer. a glass of wine, or a tot of spirits. Cigarette smoking habits were also recorded and classified as follows: never smoked cigarettes, ex-cigarette smokers, and current smokers at four levels $(1-19,20,21-39, \geqslant 40$ a day).

Water lead analyses were undertaken on 941 men (about 40 men per town). In each town men were examined over a two-week period. On two days of this period, Water Research Centre personnel invited 40 consecutive men to answer a questionnaire about their consumption of drinking water and to participate in tap water sampling from their homes. The few men who declined to participate were replaced by others seen that same day. Each man was asked to collect from the kitchen tap a litre of first-draw water first thing the next morning in a standard lead-free container. Later that same day, Water Research Centre personnel visited the man's home to collect on arrival a random daytime litre sample of water from the kitchen tap. In addition, a flushed sample was obtained after an estimated ten pipe volumes of water had been run off.

All water samples were screened by flame atomic absorption spectrometry. Results for samples greater than $200 \mu \mathrm{g} / \mathrm{l}$ were reported as measured except that the results for those samples with lead concentrations in the range 200 to $400 \mu \mathrm{g} / \mathrm{l}$ were the neans of quadruplicate measurements. Samples with lead concentrations below $200 \mu \mathrm{g} / \mathrm{l}$ were analysed by electrothermal atomisation-atomic absorption spectrometry. The choice of these procedures enabled the targets for analytical performance to be maintained.

The mean water hardness for each town was estimated from the same tap water samples. The hardness for each sample was calculated from the calcium and magnesium concentrations determined on an inductively coupled plasma emission quantometer.

\section{Results}

BLOOD LEAD

Figure 1 shows the distribution of blood lead concentrations for all 7378 men. The mean blood lead is $0.74 \mu \mathrm{mol} / \mathrm{l}$. The European Community requires that in statutory surveys blood lead concentrations should exceed $1.7 \mu \mathrm{mol} / \mathrm{l}(35 \mu \mathrm{g} / 100$ $\mathrm{ml}$ ) in at most $2 \%$ of any group surveyed. ${ }^{4}$ In this study $74 \mathrm{men}(1 \%)$ had blood lead $>1.7 \mu \mathrm{mol} / \mathrm{l}$ and only one man had blood lead exceeding $3.0 \mu \mathrm{mol} / \mathrm{l}$. The distribution is slightly skewed to the right, as has been found in other populations.
WATER LEAD

Table 1 shows the distributions of tap water lead for the three types of sample (first draw, daytime, and flushed). Most households had very low water lead concentrations for all three types of sample. Nevertheless, $5 \cdot 6 \%$ of first draw samples and $3.0 \%$ of daytime samples exceeded $100 \mu \mathrm{g} / \mathrm{l}$, the World Health Organisation's general standard for water lead concentration. ${ }^{5}$ This compares with $9.0 \%$ and $4.3 \%$ respectively in a previous national survey by the Department of the Environment. ${ }^{6}$ Such a difference is not surprising since our households are confined to 24 towns which provide less comprehensive national coverage-for example, large conurbations are not included. One per cent of households had first-draw water lead $>300 \mu \mathrm{g} / \mathrm{l}$, the WHO standard for water lead after 16 hours' contact with lead pipes. ${ }^{5}$

\section{Table 1 Water lead distributions}

\begin{tabular}{|c|c|c|c|}
\hline $\begin{array}{l}\text { Water lead } \\
\text { concentration } \\
(\mu g / l)\end{array}$ & $\begin{array}{l}\text { First } \\
\text { draw }\end{array}$ & Daytime & Flushed \\
\hline $\begin{array}{l}<10 \\
10- \\
50- \\
100- \\
\\
\geqslant 300 \\
\text { Total }\end{array}$ & $\left.\begin{array}{r}554 \\
264 \\
70 \\
41 \\
12\end{array}\right\} 5 \cdot 6 \%$ & $\left.\begin{array}{r}650 \\
225 \\
37 \\
23 \\
5 \\
540\end{array}\right\} 3.0 \%$ & $\left.\begin{array}{r}819 \\
90 \\
9 \\
10 \\
2\end{array}\right\} 1 \cdot 3 \%$ \\
\hline
\end{tabular}

WHO recommended standard $=100 \mu \mathrm{g} / \mathrm{l}$.

WHO "first draw" standard $=300 \mu \mathrm{g} / \mathrm{l}$.

TOWN DIFFERENCES IN BLOOD LEAD AND WATER LEAD

Table 2 shows the 24 towns ranked according to their mean blood lead. The variation between towns is very substantial: three towns (Ayr, Harrogate, and Wigan) had mean blood lead $>0.9 \mu \mathrm{mol} / 1$ while four towns had mean blood lead $<0.6 \mu \mathrm{mol} / \mathrm{l}$. The towns

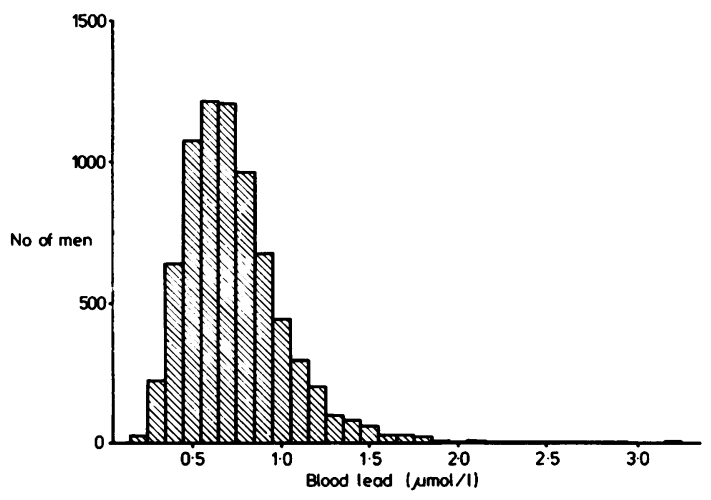

Fig 1 Distribution of blood lead for 7378 middle-aged men. 
Table 2 Blood lead and water lead in 24 towns

\begin{tabular}{|c|c|c|c|c|c|c|c|c|c|c|}
\hline \multirow[b]{3}{*}{ Town } & \multicolumn{3}{|c|}{ Blood lead } & \multirow{3}{*}{$\begin{array}{l}\text { No of } \\
\text { households }\end{array}$} & \multicolumn{6}{|c|}{ Tap water lead $(\mu g / l)$} \\
\hline & \multirow{2}{*}{$\begin{array}{l}\text { No of } \\
\text { men }\end{array}$} & \multirow{2}{*}{$\begin{array}{l}\text { Mean* } \\
(\mu \mathrm{mol} / \mathrm{l})\end{array}$} & \multirow{2}{*}{$\begin{array}{l}\text { No with } \\
\text { blood lead } \\
>1.7 \mu \mathrm{mol} / \mathrm{l}\end{array}$} & & \multicolumn{3}{|c|}{ First draw sample } & \multicolumn{3}{|c|}{ Daytime sample } \\
\hline & & & & & $50 \mu \mathrm{mol} / \mathrm{l}-$ & $100-$ & $300-$ & $50-$ & $100-$ & $300-$ \\
\hline Ayr & 257 & 0.992 & $21(8 \%)$ & 40 & 1 & 7 & 7 & 1 & 8 & 4 \\
\hline Harrogate & 273 & 0.990 & 7 & 40 & 5 & 7 & 0 & 5 & 0 & $\mathbf{0}$ \\
\hline Wigan & 333 & 0.941 & 12 & 39 & 6 & 11 & 2 & 9 & 3 & 1 \\
\hline Burnley & 274 & $0 \cdot 896$ & 7 & 40 & 6 & 0 & 0 & 2 & $\mathbf{0}$ & 0 \\
\hline Dewsbury & 323 & 0.890 & 4 & 39 & 1 & 2 & 1 & 1 & 0 & 0 \\
\hline $\begin{array}{l}\text { Merthyr Tydfil } \\
\text { Newcastle }\end{array}$ & 268 & $0 \cdot 868$ & 6 & 40 & 3 & 1 & 1 & 0 & 2 & $\mathbf{0}$ \\
\hline under Lyme & 276 & 0.851 & 2 & 38 & 4 & 0 & 0 & 2 & 1 & 0 \\
\hline Southport & 318 & 0.793 & 1 & 40 & 4 & 0 & 0 & 2 & 0 & 0 \\
\hline Lowestoft & 317 & 0.774 & 2 & 41 & 6 & 3 & 0 & 3 & 1 & 0 \\
\hline Falkirk & 277 & 0.768 & 2 & 39 & 0 & 0 & 0 & 0 & 0 & 0 \\
\hline Shrewsbury & 307 & 0.765 & 2 & 39 & 0 & 0 & 0 & 0 & 0 & 0 \\
\hline Mansfield & 318 & 0.748 & 0 & 39 & 1 & 0 & 0 & 0 & 0 & 0 \\
\hline Exeter & 330 & 0.732 & 2 & 39 & 7 & 1 & 0 & 0 & 1 & 0 \\
\hline Scunthorpe & 328 & 0.677 & 0 & 40 & 2 & 3 & 1 & 2 & 2 & 0 \\
\hline Darlington & 345 & 0.666 & 1 & 40 & 1 & 1 & 0 & 0 & 1 & 0 \\
\hline Carlisle & 365 & 0.649 & 0 & 38 & 4 & 1 & $\mathbf{0}$ & 1 & 1 & 0 \\
\hline Gloucester & 262 & 0.641 & 1 & 38 & 5 & 1 & 0 & 2 & 1 & 0 \\
\hline Dunfermline & 321 & 0.625 & 0 & 40 & 4 & 1 & 0 & 3 & 1 & 0 \\
\hline Maidstone & 309 & 0.606 & 1 & 38 & 1 & 0 & 0 & 0 & 0 & 0 \\
\hline Bedford & 286 & 0.596 & 0 & 37 & 3 & 0 & 0 & 0 & 0 & 0 \\
\hline Hartlepool & 311 & 0.556 & 0 & 38 & 3 & 0 & 0 & 0 & 1 & 0 \\
\hline Grimsby & 309 & 0.556 & 2 & 39 & 0 & 0 & 0 & 1 & 0 & 0 \\
\hline Ipswich & 356 & 0.553 & 1 & 40 & 1 & 2 & 0 & 3 & 0 & 0 \\
\hline All towns & 7378 & 0.738 & $74(1 \%)$ & 941 & 70 & $4 \overline{1}$ & 12 & 37 & 23 & 5 \\
\hline
\end{tabular}

*For every town the standard error of mean blood lead was less than $0.03 \mu \mathrm{mol} / \mathrm{l}$.

'with higher mean blood lead also had a higher proportion of men with blood lead $>1.7 \mu \mathrm{mol} / 1-$ for example, $8 \%$ in Ayr, $4 \%$ in Wigan, and 3\% in Harrogate and Burnley.

We recognise that evaluation of blood lead was determined over a different time period in each town, so that both seasonal and analytical variation cannot be totally eliminated when comparing town means for blood lead. Nevertheless, we consider such potential bias is likely to be small compared with the wide range of town means observed in table 2 .

Table 2 also shows the frequency of high water lead concentrations for the first draw and daytime tap water samples in each town, based on approximately 40 of the men's households per town. Evidently, the occurrence of high water lead concentrations is largely confined to the three towns with the highest mean blood lead. For example, there were 53 first draw samples with $\geqslant 100 \mu \mathrm{g} / \mathrm{l}$ of lead and 34 of these (64\%) occurred in Ayr, Harrogate, and Wigan. The 40 households in Ayr included some very high water lead concentrations: three households had first draw water lead $>1000 \mu \mathrm{g} / \mathrm{l}$, the highest being $2660 \mu \mathrm{g} / \mathrm{l}$. The group general practice used in Ayr was in the south-west of the town, as were most of the men's households. This area had a very acidic water supply that is now being treated to reduce plumbosolvency.
RELATION BETWEEN INDIVIDUAL BLOOD LEAD AND WATER LEAD

Both blood lead and household tap water lead were available for 910 men surveyed. Table 3 shows the mean blood lead for these men classified into four intervals of first draw and daytime water lead. In each case the mean blood lead is notably higher for men with high household water lead concentrations. For instance, the 12 men with first draw water lead $\geqslant 300$ $\mu \mathrm{g} / \mathrm{l}$ have mean blood lead more than double that for the 789 men with first draw water lead $<50 \mu \mathrm{g} / \mathrm{l}$. Even the 69 men with first draw water lead from $50-100 \mu \mathrm{g} / 1$ have a $25 \%$ increase in mean blood lead. It should be noted, however, that these are trends in mean blood lead. As indicated by the standard deviations in table 3 there is considerable overlap between the water lead groupings as regards individual blood lead, so that at each water lead concentration there exists a wide spread of blood lead values.

It is interesting to note the numbers of men with raised blood lead $(>1.7 \mu \mathrm{mol} / \mathrm{l})$ in each water lead category (table 3). In particular, only 64 men (7\%) have daytime water lead $\geqslant 50 \mu \mathrm{g} / \mathrm{l}$, but these include 10 of the 16 men $(63 \%)$ with blood lead $>1.7 \mu \mathrm{mol} / \mathrm{l}$. This indicates that if a man has a raised blood lead there is a reasonable chance that his household has a high tap water lead concentration. 
Table 3 Individual blood lead and water lead

\begin{tabular}{lclll}
\hline $\begin{array}{l}\text { First draw } \\
\text { water lead } \\
(\mu \mathrm{g} / \mathrm{l})\end{array}$ & $\begin{array}{l}\text { 'No of } \\
\text { men }\end{array}$ & $\begin{array}{l}\text { Mean } \\
\text { blood lead } \\
(\mu \mathrm{mol} / \mathrm{l})\end{array}$ & $\begin{array}{l}\text { Standard } \\
\text { deviation }\end{array}$ & $\begin{array}{l}\text { No with } \\
\text { blood lead } \\
>1 \cdot 7 \mu \mathrm{mol} / \mathrm{l}\end{array}$ \\
\hline$<50$ & 789 & 0.727 & 0.267 & 6 \\
$50-$ & 69 & 0.912 & 0.353 & 3 \\
$100-$ & 40 & 1.045 & 0.378 & 3 \\
$\geqslant 300$ & 12 & 1.650 & 0.737 & 5 \\
Total & 910 & 0.767 & 0.317 & 17 \\
$\begin{array}{l}\text { Daytime } \\
\text { water lead }\end{array}$ & & & & \\
$(\mu g / l):$ & & & & \\
$<50$ & 845 & 0.739 & 0.272 & 6 \\
$50-$ & 36 & 0.947 & 0.381 & 3 \\
$100-$ & 23 & 1.196 & 0.467 & 4 \\
$\geqslant 300-$ & 5 & 1.920 & 0.766 & 3 \\
Total & 909 & 0.765 & 0.311 & 16 \\
\hline
\end{tabular}

It is relevant to consider the form of relation between blood lead and household water lead. Figure 2 indicates one approach to this problem. Men have been grouped into nine intervals of first draw water lead. The first interval comprises $\mathbf{4 7 3}$ men with low water lead $(\leqslant 6 \mu \mathrm{g} / \mathrm{l})$ while the other eight intervals are each chosen to include about 50 men. Figure 2 shows mean blood lead for men in each interval plotted against their mean first draw water lead. The impression is that mean blood lead increases linearly with first draw water lead except for the last group with very high water concentrations. The regression line shown in fig 2 is for all men with water lead $<100 \mu \mathrm{g} / \mathrm{l}$-that is, excluding the last group of high water leads. The regression equation is predicted blood lead $=0.699+0.0030 \times$ first draw water lead. For water lead concentration of $100 \mu \mathrm{g} / 1$ the estimated blood lead is $1.00 \mu \mathrm{mol} / \mathrm{l}$, which is $43 \%$ higher than the intercept level of $0.70 \mu \mathrm{mol} / 1$ at zero water lead.

This simple linear relation, however, does not appear to be maintained at higher levels of first draw water lead. A separate regression for the 49 men with water lead $>100 \mu \mathrm{g} / \mathrm{l}$ has slope $=0.7 \times 10,-3$ which is only $23 \%$ of the slope for water lead $\leqslant 100 \mu \mathrm{g} / \mathrm{l}$. This indicates that the increase in blood lead becomes proportionately much smaller as water lead continues to rise. For example, if one were ill advised enough to extrapolate the regression line in fig 2 to water lead $>100 \mu \mathrm{g} / \mathrm{l}$ then the resultant predicted mean blood lead for these 49 "high water lead" men would be $1.68 \mu \mathrm{mol} / 1,39 \%$ higher than their actual mean blood lead of $1.21 \mu \mathrm{mol} / \mathrm{l}$.

\section{BLOOD LEAD AND WATER HARDNESS}

It has been suggested that blood lead levels may be higher in soft water areas, and that this association cannot be solely attributed to domestic water lead concentrations. ${ }^{7}$ Figure 3 shows each town's mean blood lead plotted against mean water hardness and indicates a pronounced negative association $(r=-0 \cdot 67)$. The six towns with highest mean blood lead all have soft water supplies, while the five towns with lowest mean blood lead all have hard water supplies.

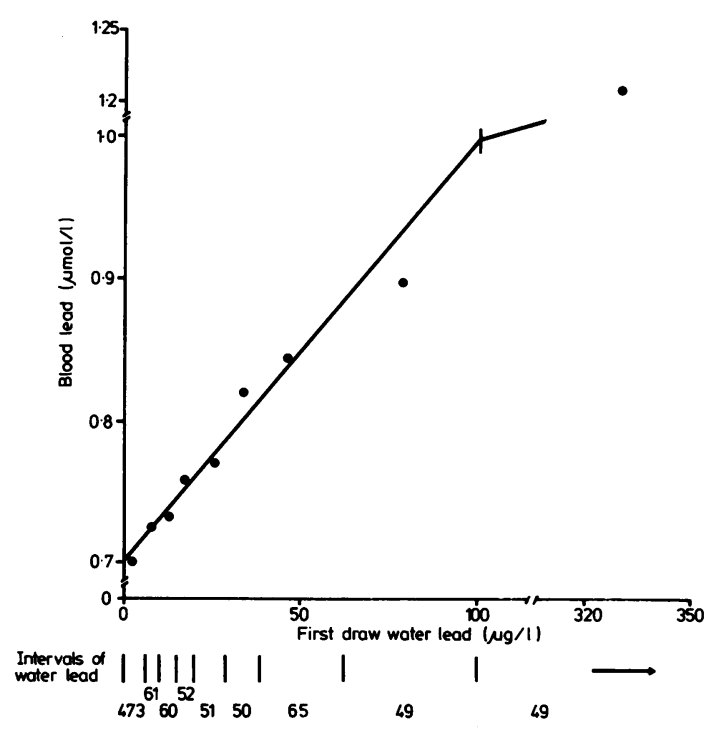

Fig 2 Mean blood lead for men grouped by first draw water concentration.

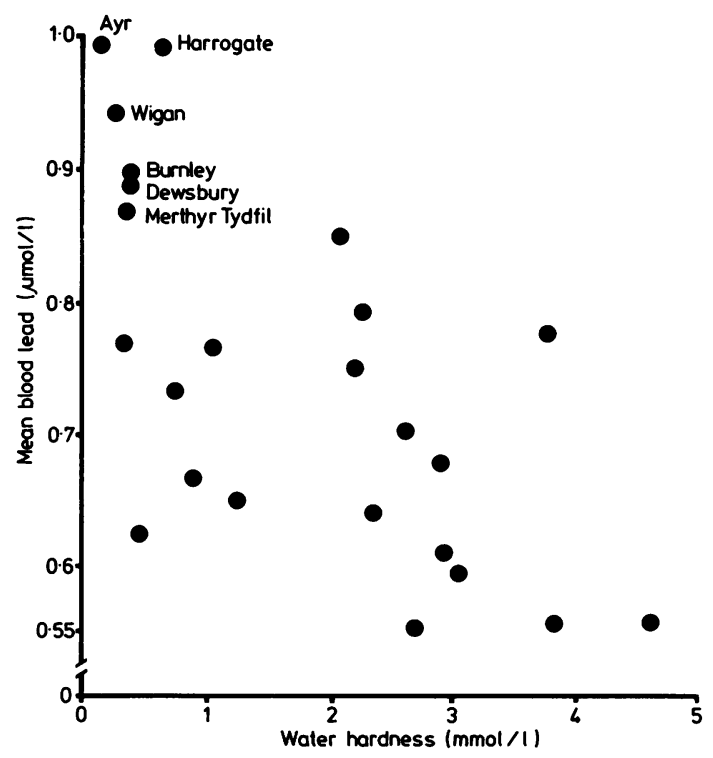

Fig 3 Mean blood lead and water hardness in 24 towns. 
Some of the soft water towns-for example, Ayr, Wigan, and Harrogate-have households with high water lead concentrations so that one needs to consider whether the above blood lead/water hardness relationship is merely reflecting the impact of domestic water lead on blood lead. Therefore, out of the $\mathbf{4 0}$ men per town with household water lead measured we have selected those with first draw water lead $<10 \mu \mathrm{g} / \mathrm{l}$ to compute an estimated mean blood lead per town for men with low domestic water lead concentrations. These means are based on an average of only 24 men per town and hence are not precise town estimates, but there still exists a substantial negative correlation with water hardness $(\mathrm{r}=-0.56, \mathrm{p}<0.01)$.

BLOOD LEAD, ALCOHOL, AND CIGARETTES We have previously reported that for men in this study blood lead concentrations have a positive association with alcohol consumption and cigarette smoking. ${ }^{8} \mathrm{We}$ have used multiple regression to assess simultaneously the effects of water lead, alcohol, and cigarettes on blood lead for the 910 men for whom all this information was available. The results are shown in table 4. Water lead has been fitted as two straight lines (as in fig 2) while alcohol consumption and cigarette smoking are classified into eight and six categories respectively. The interpretation of table 4 may best be explained by a couple of examples. Men with no lead in their tap water who do not drink alcohol or smoke cigarettes have a predicted mean blood lead concentration of $0.571 \mu \mathrm{mol} / \mathrm{l}$, but a man with first draw water lead $=100 \mu \mathrm{g} / \mathrm{l}$ who has more than six alcoholic drinks a day and smokes 40 or more cigarettes a day has predicted blood lead $=0.571+0.00314 \times 100+0.156+0.158$ $=1 \cdot 20 \mu \mathrm{mol} / \mathrm{l})$. This illustrates the extent to which the presence of lead in the domestic water supply combined with heavy drinking and smoking can considerably increase a man's blood lead concentration.

\section{Discussion}

This study is unique in providing information on blood lead and household water lead concentrations on a large sample of British men that may be linked to a wide range of other measurements, in particular relating to cardiovascular disease. Although only men aged 40-59 are included, it is reasonable that many of the conclusions can be generalised to both sexes and other age groups. The random selection of men from one group general practice in each of 24 towns plus the wide geographical coverage means that the findings are of considerable relevance to the whole British population.

\section{TAP WATER LEAD}

It is reassuring to find that blood lead concentrations were generally quite low, with only $1 \%$ of men having blood lead $>1.7 \mu \mathrm{mol} / \mathrm{l}$. Nevertheless, the substantial between-town difference in mean blood lead suggests that environmental exposure to lead varies considerably from one area to another. Lead piping for household water supplies can raise water lead concentrations, especially if the water is acidic. ${ }^{69}$ Several studies have shown that this can substantially increase the inhabitants' body burden of lead. ${ }^{10-12}$ This study has gone one step further by showing that the towns with highest water lead concentrations, such as Ayr and Wigan, tend to have the highest mean blood lead concentrations, which suggests that exposure to lead in drinking water is a major determinant of whether a community's body burden of lead is above or below average. Clearly the identification of areas with high water lead concentrations so that plumbosolvency could be alleviated-for example, by chemical treatment of source water to raise $\mathrm{pH}$-is urgent, and this is fully accepted by the water industry.

It is of particular importance to identify why individuals have unduly high blood lead concentrations. In this regard table 3 showed that

Table 4 Regression of blood lead on first draw water lead, alcohol consumption, and cigarette smoking

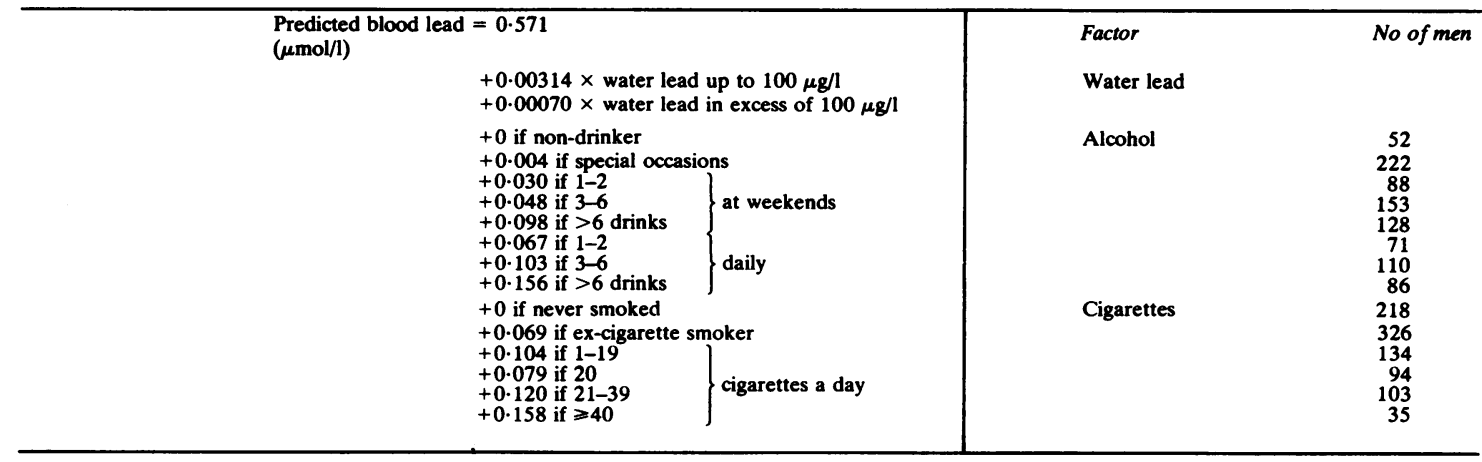


most men with raised blood lead $(>1.7 \mu \mathrm{mol} / \mathrm{l})$ had a daytime household water lead concentration $\geqslant 50$ $\mu \mathrm{g} / \mathrm{l}$, which suggests that in individual adults high domestic water lead may be the most important cause of raised blood lead concentrations.

We have been able to clarify the shape of the relationship between blood lead and household water lead. As indicated in fig 2, mean blood lead increases linearly with first draw water lead up to around $100 \mu \mathrm{g} / \mathrm{l}$, but the rate of increase in blood lead is much reduced above that level. One can speculate that the relationship gradually deviates from linearity as water lead increases, with an ever decreasing slope. The precise form of this underlying relationship, however, cannot be accurately determined since there exists enormous variation in individual blood lead at any specified level of water lead and also sampling variation in first draw water lead.

Our regression analyses have not made special allowance for variability in the sampling and measurement of water lead so that we may have slightly underestimated the slope of the underlying relationship between blood lead and water lead. Also, differing quantities and times of water consumption may affect individual blood lead concentrations: these issues are currently being investigated.

This study confirms that the relation is not linear at higher levels. Previous research had suggested a power function relationship-for example, blood lead increases as the cube-root of water lead. ${ }^{10}$ Our data, based on a large and more representative sample of men, do not agree with such a curve, particularly at low concentrations of water lead. Why should high water lead concentrations fail to produce the same proportionate increase in blood lead? Perhaps such a high concentration of lead is only partially absorbed when drunk or used for cooking.

Most of the results presented have been in terms of first draw rather than daytime water lead. The latter concentration tends to be on average about half that of the former. The timing of the daytime water sample is arbitrary-that is, one has no control over the time since water was last flushed, and hence the daytime sample has poorer reproducibility than a first draw sample. This may account for the first draw sample having a slightly stronger correlation with blood lead $(r=0.39$ compared with $r=0.32$ for the daytime water lead).

From fig 2 we have estimated that as first draw water lead increases from 0 to $100 \mu \mathrm{g} / \mathrm{l}$ mean blood lead increases from 0.7 to $1.0 \mu \mathrm{mol} / \mathrm{l}$. The chance of an individual having blood lead $>1.7 \mu \mathrm{mol} / \mathrm{l}$ increases from under $1 \%$ to over $5 \%$. These findings emphasise that inhabitants of households with first draw water lead around $100 \mu \mathrm{g} / \mathrm{l}$ do have a considerably increased risk of excess lead exposure. One should consider therefore whether the WHO recommendation, that first draw water lead should not exceed $300 \mu \mathrm{g} / \mathrm{l}$ in households with lead piping, should be lowered. For the United Kingdom this tightening of standard may be achieved by the qualifying comment in the impending European Community directive, which requires that where lead pipes are present, the lead concentration in water must not exceed $100 \mu \mathrm{g} / 1$ "frequently or to an appreciable extent." The exact interpretation of this statement, however, has yet to appear.

Mean blood lead for all $7378 \mathrm{men}$ was $0.74 \mu \mathrm{mol} / \mathrm{l}$ compared with an estimated $0.70 \mu \mathrm{mol} / 1$ at zero water lead. This suggests that nationally lead in drinking water contributes on average around $6 \%$ of the total exposure to lead. Since high water lead is very unevenly distributed, however, being predominantly encountered in households with lead pipes and an acidic water supply, this average exposure is an inadequate reflection of the dramatic effects in some individuals.

\section{ALCOHOL AND CIGARETTES}

It is particularly useful to consider simultaneously the contributions of alcohol, cigarettes, and water lead to an individual's blood lead concentration, as shown in the regression analysis of table 4 . These findings imply that mean blood lead in middle-aged men could be reduced to $0.57 \mu \mathrm{mol} / \mathrm{l}$ if they all refrained from both alcohol and cigarettes and if water lead was eliminated. This is to be compared with an overall mean blood lead of $0.74 \mu \mathrm{mol} / \mathrm{l}$, which suggests that these three factors collectively contribute on average an estimated $23 \%$ to the blood lead concentration in adults. These contributions may be separated as $9 \%$ due to cigarettes, $8 \%$ due to alcohol, and $6 \%$ due to lead in drinking water (as already estimated above). Such estimates for alcohol and cigarettes are calculated by applying the predicted values in table 4 to the observed numbers of men in each drinking and smoking category.

These estimated average contributions apply to the whole population of middle-aged men. For those individuals who drink and smoke heavily on a daily basis, our evidence indicates that blood lead concentrations may typically increase by over $50 \%$ as a consequence. If such a person's domestic water lead is also raised then the combination of these three factors may result in a doubling of that person's blood lead concentration.

Possible explanations for the effects of alcohol and cigarettes have been discussed elsewhere. ${ }^{8}$ These associations cannot be explained away by other factors-for example, town of residence, age, social class. Indeed, inclusion of such factors in the multiple 
regression made little difference to the estimated effects of alcohol, smoking, and water lead. Similar associations for alcohol and smoking have been reported in Denmark ${ }^{13}$ and for smoking by the Department of the Environment. ${ }^{4}$

It is of some interest to recall that blood-lead concentrations tend to be higher in men than women and that during adolescence, the blood-lead concentrations of boys but not girls rises quite sharply. ${ }^{14} 15$ Thereafter blood lead for both men and women shows a slow rise to middle age. Smoking cigarettes and drinking alcohol could possibly account for the male/female difference.

\section{WATER HARDNESS}

The negative association between a town's water hardness and mean blood lead concentration (fig 3 ) is of interest. It cannot be explained simply in terms of differing household water lead concentrations, although it remains possible in soft water areas that non-household water supplies-for example, at workplaces and canteens-may contribute to blood lead concentrations. Recent experimental studies in man $^{16}$ show that moderate amounts of calcium and phosphate in water considerably reduce the uptake of lead, whereas calcium by itself has little effect. These studies also show that the percentage uptake of lead from food is very small compared with the percentage uptake of lead from water. They conclude that lead in water and other drinks taken without food is likely to contribute proportionately more to uptake than lead in food.

Even after allowing for differences in water lead, alcohol consumption, cigarette smoking, and water hardness, inter-town variation in blood lead concentrations still remains. We have no measure of lead from non-water sources-for instance, food, petrol, air, and dust-in each town, so that no simple explanation can be given.

\section{Conclusion}

We have clearly shown that individuals exposed to raised water lead concentrations have a pronounced increase in blood lead concentrations. In addition, our findings emphasise that life-style habits such as alcohol and smoking substantially contribute to blood lead concentrations. Direct evidence of a comparable nature has not been shown for lead in petrol. It seems reasonable that lead in water should be given priority in any national campaign to reduce lead exposure.

The British Regional Heart Study is supported by a programme grant from the Medical Research Council. The water sampling and analysis were carried out by the Water Research Centre under contracts to the Department of the Environment and the Commission of the European Communities (contract No 246-77-1 ENV UK), whose permissions to publish are gratefully acknowledged. We are grateful to Mrs Jackie Gwyn for typing the manuscript.

\section{References}

${ }^{1}$ Anonymous. Lead in petrol and elsewhere. Lancet 1982; i: $1337-8$.

${ }^{2}$ Shaper AG, Pocock SJ, Walker M, Cohen NM, Wale CJ, Thomson AG. British Regional heart study: cardiovascular risk factors in middle aged men in 24 towns. Br Med J 1981; 283: 179-86.

${ }^{3}$ Delves HT. A micro-sampling method for the rapid determination of lead in blood by atomic absorption spectrophotometry. Analyst 1970; 95: 431-8.

${ }^{4}$ Department of the Environment. Central Directorate on Environmental Pollution. European community screening programme for lead: United Kingdom results for 1979-80. London: Department of the Environment, 1981.

${ }^{5}$ World Health Organisation. International standards for drinking water. 3rd ed. Geneva: WHO, 1971.

- Department of the Environment. Lead in drinking water: a survey in Great Britain, 1975-6. Pollution paper No 12. London:HMSO, 1977.

${ }^{7}$ Thomas HF, Elwood PC, Toothill C, Morton M. Blood and water lead in a hard water area. Lancet 1981; i: 1047-8.

${ }^{8}$ Shaper AG, Pocock SJ, Walker M, et al. Effects of alcohol and smoking on blood lead in middle-aged British men. Br Med J 1982; 284: 299-302.

'Pocock SJ. Factors influencing household water lead: a British national survey. Arch Environ Health 1980; 35: 45-51.

${ }^{10}$ Moore MR, Meredith PA, Campbell BS, Goldberg A, Pocock SJ. Contribution of lead in drinking water to blood lead. Lancet 1977; ii: 661-2.

${ }^{11}$ Thomas HF, Elwood PC, Welsby E, St Leger AS. Relationship of blood lead in women and children to domestic water lead. Nature 1979, 282: 712-3.

${ }^{12}$ Moore MR, Goldberg A; Meredith PA, Lees R. Low RA, Pocock SJ. The contribution of drinking water lead to maternal blood lead concentrations. Clin Chim Acta 1979; 95: 129-33.

${ }^{13}$ Grandjean $P$, Olsen NB, Hollnagil $H$. Influence of smoking and alcohol consumption on blood lead levels. Int Arch Occup Environ Health 1981; 48: 391-7.

${ }^{14}$ Department of the Environment. Lead pollution in Birmingham. Pollution paper No 14. London: HMSO, 1978.

${ }^{15}$ Mahaffey KR, Annest JL, Barbano HE, Murphy RS. Preliminary analysis of blood-lead concentrations for children and adults: HANES II, 1976-8. In: Hemphill DD, ed. Trace substances in environmental health-XII, a symposium. Columbia: University of Missouri, 1979.

${ }^{16} \mathrm{Heard}$ MJ,Chamberlain KC. Effects of minerals and food on uptake of lead from gastrointestinal tract in humans. Human Toxicology 1982; 1: 411-5. 